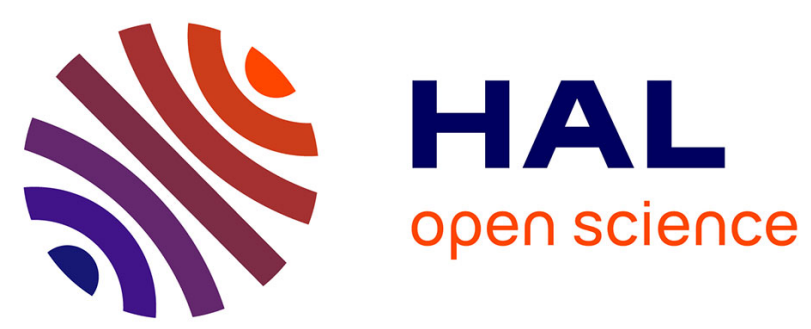

\title{
3D MODELS OVER THE CENTURIES: FROM OLD FLOOR PLANS TO 3D REPRESENTATION
}

\author{
Christophe Riedinger, Michel Jordan, Hedi Tabia
}

\section{To cite this version:}

Christophe Riedinger, Michel Jordan, Hedi Tabia. 3D MODELS OVER THE CENTURIES: FROM OLD FLOOR PLANS TO 3D REPRESENTATION. International Conference on 3D Imaging - IC3D 2014, Dec 2014, Liège, Belgium. hal-01093770

\section{HAL Id: hal-01093770 https://hal.science/hal-01093770}

Submitted on 11 Dec 2014

HAL is a multi-disciplinary open access archive for the deposit and dissemination of scientific research documents, whether they are published or not. The documents may come from teaching and research institutions in France or abroad, or from public or private research centers.
L'archive ouverte pluridisciplinaire HAL, est destinée au dépôt et à la diffusion de documents scientifiques de niveau recherche, publiés ou non, émanant des établissements d'enseignement et de recherche français ou étrangers, des laboratoires publics ou privés. 


\title{
3D MODELS OVER THE CENTURIES: FROM OLD FLOOR PLANS TO 3D REPRESENTATION
}

\author{
Christophe Riedinger, Michel Jordan and Hedi Tabia
}

\author{
ETIS, UMR8051, ENSEA, Université Cergy-Pontoise, CNRS, F 95000 CERGY \\ michel.jordan@u-cergy.fr, hedi.tabia@ensea.fr
}

\begin{abstract}
This paper presents a set of algorithms dedicated to the 3D modeling of historical buildings from a collection of old architecture plans, including floor plans, elevations and cutoffs. Image processing algorithms help to detect and localize main structures of the building from the floor plans (thick and thin walls, openings). The extrusion of the walls allow us to build a first 3D model. We compute height informations and add textures to the model by analyzing the elevation images from the same collection of documents. We applied this pipeline to XVIII ${ }^{\text {th }}$ century plans of the Château de Versailles, and show results for two different parts of the Château.
\end{abstract}

Index Terms - Cultural heritage, 3D Restitution, Image Processing, Image Segmentation, 3D Application.

\section{INTRODUCTION}

3D models are very common in a wide area of domains, including design and architecture, industries, entertainments, etc. Also in the cultural heritage domain, they are more and more useful for archeologists and historians, as well as curators. Most of 3D models for culture heritage are built from laser scanning and/or photogrammetry [5, 20, 15, 13] (in [18], interested readers will find a review of various techniques which were used in the beginning of the $\mathrm{XXI}^{\text {st }}$ century). Recent 3D laser scanning techniques combined with photography augmented reality algorithms, allow to build very impressive models, involving accurate geometry and realistic texture mappings, as in [1] which main objectives are the preservation and the promotion of the cultural heritage. Laser scanning is also combined with CAD softwares and image processing techniques in order to build 3D models of partially disappeared monuments $[4,10]$. These techniques involve a great amount of manual operations not only in the 3D digitization steps but also in the virtual/augmented reality steps.

But what could be done when the building or monument has been partially or completely destroyed, or when a lot of transformations and changes have modified its appearance or indoors? Usually, a lot of old floor plans and other graphic documents help historians to know these transformations, and to imagine the disappeared appearance of the most important monuments.

The aim of our work is to propose a pipeline for 3D model generation from old floor plans of historical castles, oldmansions or other interesting monuments. Among the difficulties of the task we are coping with, are some specific features of these old documents ( $c f$. fig 1) due to drawing as well as digitization: straight lines are not so straight, writings look like hand-writings, line thickness is not equal along the same line, symbols are not homogeneous, paper watermarks and foldings appear in the images, etc. The reminder of the paper is organized as follows: in section 2, we give a brief review of automatic analysis of architectural plans; section 3 gives the method overview, the 2D floor plan processing is detailed in section 4 , and section 5 presents the 3D model extrusion algorithm. In section 6, we present some 3D model captures of the Château de Versailles, and conclusions and future developments end the paper (section 7).

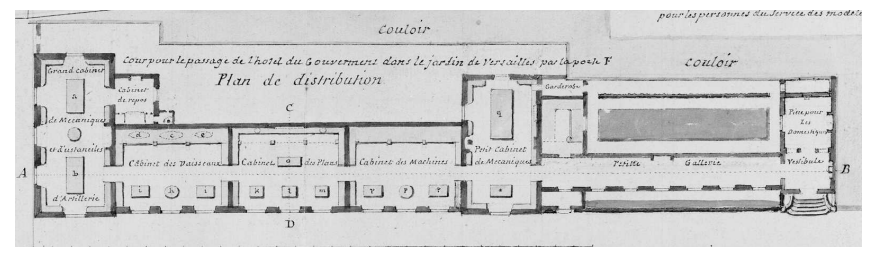

Fig. 1. Floor plans of an historical castle (XVIII ${ }^{\text {th }}$ century).

\section{RELATED WORK}

The use of 3D representation is very helpful for architects. It gives them a more intuitive perspective on their work, and moreover allows to conduct large sets of studies related to lighting, heat transfer, radio waves propagation, etc. Automatic generation of 3D models from 2D architectural drawings is a quite active research field since the end of $\mathrm{XX}^{\text {th }}$ century [19]. Architectural floor plans are generally composed of geometric shapes (straight lines, curves) representing the building structure (external and inner walls), while various symbols represent openings, heating and furniture elements, etc. A lot of textual annotations gives information about the 
building use, rooms, dimensions...

The most common automatic approaches consist first in seperating graphics and texts in the images. The detection of straight lines (segments) allow to localize thick and thin walls, either by using mathematical morphology or Hough transforms $[6,11]$. 3D models can be built therefore by analyzing the connectivities of the segments and searching for their internal relationships [12]. Key symbols are recognized [8] and interpreted [21]. Looking for approximatively convex regions [11] or SURF key-point extraction [2] help users to find room boundaries, and applying OCR to the text layer gives the room functions [2]. Finally, walls are extruded in order to provide the 3D model of the building. In [16], Lu et al. present a system for generating 3D models from "architect drawings", i.e. sketches ordinary used by the architects to describe their primary works. These drawings are divided in 3 categories: structural (building structures), functional (doors, windows, elevators, etc.), and decorative (dividing walls, lights, etc.). The presented system uses 3 main steps to process the drawings: shape analysis and recognition allow to detect structural elements; the graphic primitives corresponding to the recognized shapes are removed; and finally a symbol recognition algorithm detect architectural entities.

However, as explained in section 1, we are facing some drawbacks that do not allow us to directly use these algorithms to build our culture heritage 3D models. In particular, we will have to cope with not so straight "straight lines", unnormalized symbols and texts. Nevertheless, we will adapt some of the global architecture of these systems in our context, as we will explain in next section.

\section{METHOD OVERVIEW}

We propose an automated method to perform 3D reconstruction of monuments using floor plans designed by architects. The different steps of the process are summarized on figure 2 . The first part of the pipeline uses image processing algorithms in order to extract relevant informations from the floor plans (section 4): after some preprocessings (section 4.1) in order to remove noise, and reduce the amount of information (the floor plan digitized images are usually more than $8000 \times 8000$ ), we try do detect, localize and classify the building walls in the floor plan (section 4.2). We then extrude the 3D model on the basis of the walls (section 5).

The second part of the pipeline deals with the elevation and cut-off images (section 5.2); these images are used to fix the height of the 3D model, localize openings and add textures to the walls.

\section{2D FLOOR PLAN PROCESSING}

In this section, we present the $2 \mathrm{D}$ processing pipeline used in this work in order to extract relevant informations from 2D plans. We will particularly detect load-bearing walls as well as dividing walls, that we will next extrude in order to generate the 3D model.

\subsection{Preprocessings}

\subsubsection{Image resizing}

Most old architectural plans have significant size, up to 2 meters each side. Moreover, the digitization of these plans is performed with a high resolution. Depending on the resolution of the input plan and in order to increase the processing speed, the image dimensions can be reduced by a given factor $r$. Image reduction is performed in the following way: we keep the darkest pixel in each $r \times r$ vignette. Indeed, the plans that we want to extract are drawn with black pencil on white paper; thus, the dark gray levels carry the useful information for our purpose.

\subsubsection{Denoising and binarization}

Before the binarization step, we perform a denoising processing, using the Non Local Means algorithm [17]. After that the binarization step works as follows: we first compute the median value med of the gray level image $I$; as most of the plan is white paper, med is close to the background white color of the paper. For each pixel $(u, v)$, we compute, in its $3 \times 3$ neighborhood, the mean value of the absolute differences between the pixel's gray level and med, and create an image $I_{\text {diff }}$. Each pixel of the binarized image $I_{b}$ is computed as follows (let $s$ a fixed threshold parameter):

$$
\begin{array}{rc}
\text { if } I(u, v)>\text { med } & I_{b}(u, v)=0 \\
\text { if } I_{\text {diff }}(u, v)>s \times \text { med diff }_{\text {dise }} & I_{b}(u, v)=255 \\
\text { otherwise } & I_{b}(u, v)=0
\end{array}
$$

We chose the $s$ value experimentally, and checked that the binarization process is robust against its variations. The binarized image shows well contrasting edges that will be easier to detect.

\subsection{Detection and localization of building walls}

We will detect the main walls and the dividing walls in the binarized image; in this image, the walls seam as dark strokes with different thicknesses, thus we use mathematical morphology operators to detect them. This allow to use the same algorithm to detect thick walls and thin ones, only by tuning a threshold parameter. Because of the "not so straight" character of straight lines in these documents, using Hough transforms would not give relevant results.

\subsubsection{Wall detection}

We iterate a unit ball morphological erosion process, thus obtaining an image where each pixel belonging to a connex 


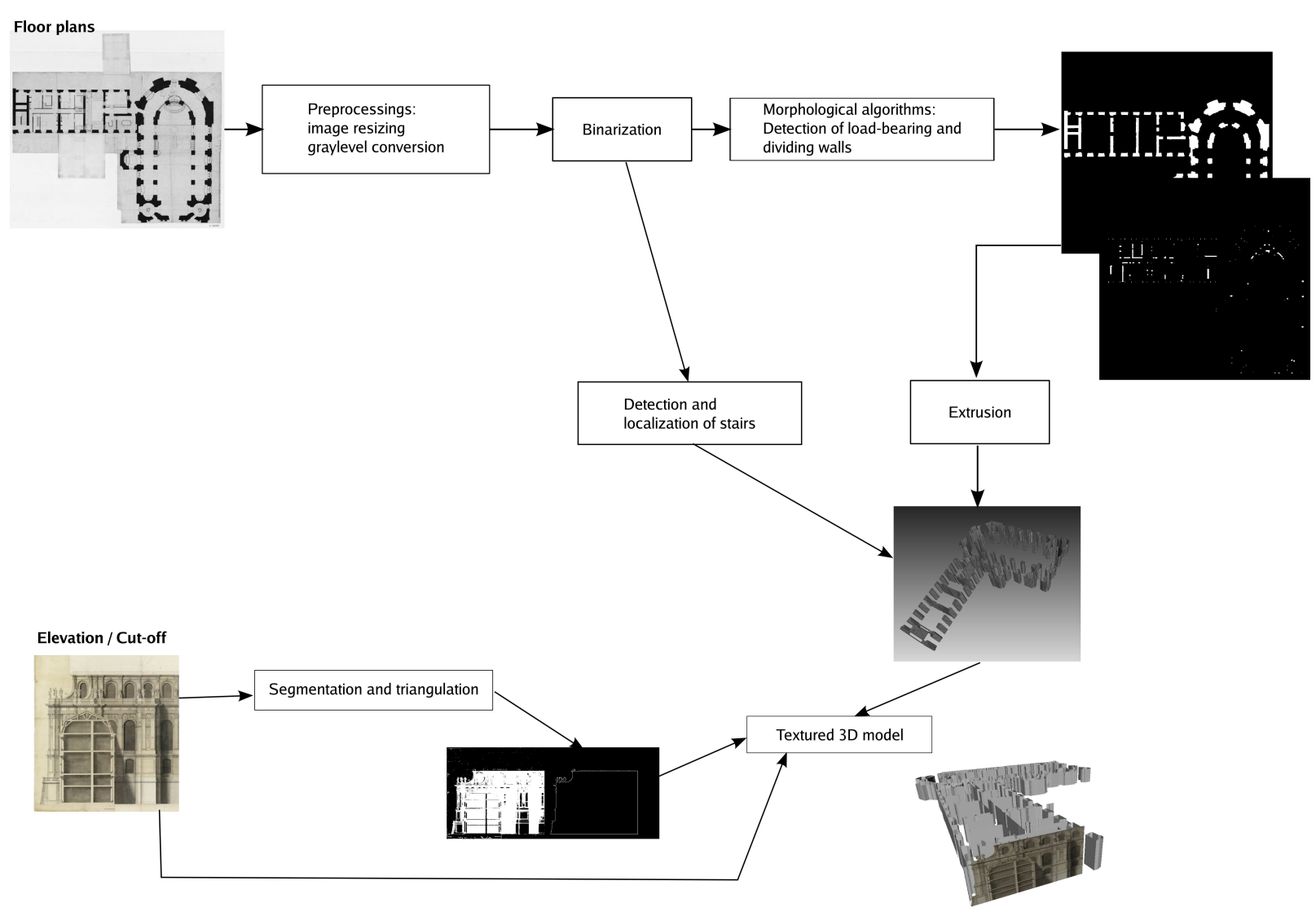

Fig. 2. Method overview.

component (wall) is labeled with its distance to the nearest boarder of the component. We use the Chebychev distance (chessboard distance, [7, 9]), which runs fast and gives satisfying results in our context. Then we select walls according to their thickness in the distance image; the figure 3 shows the main wall (left) and the dividing walls (right) detected in a floor plan of the chapelle of the Château de Versailles.
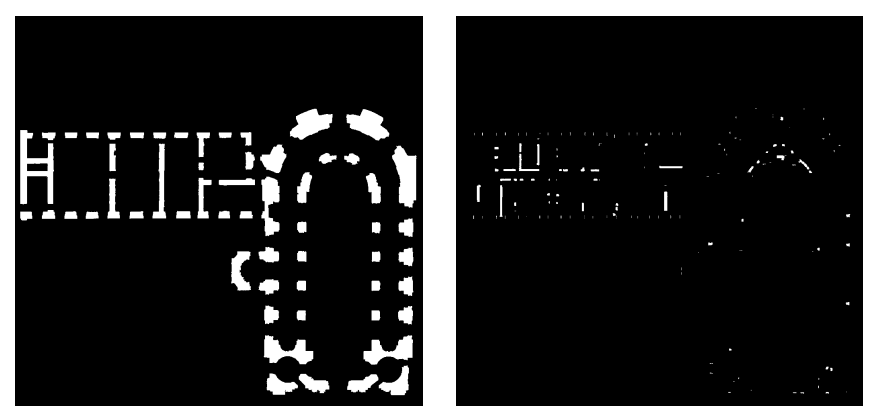

Fig. 3. Walls detected in the floor plan: (left) main walls; (right) dividing walls.

\subsubsection{Wall segmentation}

The next step consists in computing the contours of the detected walls, which will be the edges of the final 3D model. We first compute the thresholded local gradient image $I_{\text {grad }}$ of the wall image. We obtain the morphological skeleton of $I_{\text {grad }}$ by means of the $8 \mathrm{~L}$ structuring elements [14]; finally, we localize in this image the extremities of the segments (red points in figure 4, left).

To extract primary segments we perform the following procedure: we assign a label to each point in the $5 \times 5$ neighborhood of a junction if the point is at a two pixel distance of the junction (the labels and the junctions are not first neighbors). The labels are dilated iteratively with the unit ball as a structuring element. We do not modify the image points not belonging to the skeleton. After several iterations, when the image does not change any more, each label covers a part of the skeleton that is a segment between two junctions. For each segment $S$, beginning with the longest segment and finishing with the smaller one, we merge the adjacent segments to $S$ using the following criteria:

CRITERIA - Let $A$ be a segment and $B$ the segment that is to be combined with $A$; the segments are merged if and only if the distance between the barycenter of the points of $B$ and 
the line passing through $A$ is less than a given threshold.

We iterate the criteria until there is no more candidate segments. The figure 4 (right) shows segments after fusion on a small part of the original image.
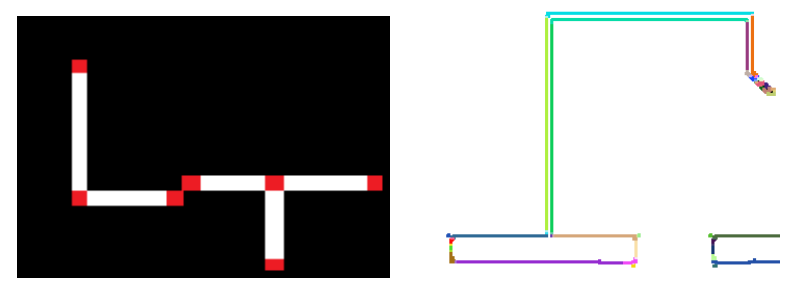

Fig. 4. Segment junctions (left), and segments after fusion (zoom, right figure).

\subsection{Detection and localization of staircases}

Staircases are an important architectural and functional element of buildings, and we defined a semi-automatic method to detect them in the floor plans. The semi-automatic method allows to deal with the unnormalized symbols in the old floor plans; we found a semi-automatic method better than a fully automated one, which would result in more erroneous detections. The user first designs a rectangular area around stairs, and the algorithm detect its shape and accurately localize it. In fact, it is easier for the user to design areas where to localize stairs than to post-process a fully automatic detection and remove false detections. Moreover the localization is faster in this way, because it deals only with small vignettes in the image.

In our plans, staircases are represented with plain strokes (for the stairs at the given floor) and hashed strokes (for the ones belonging to the up/bottom floor), see figure 5 .

The localization process works as follows: first we detect the different connex components in the set stairs-walls of the floor plan (these are the black pixels figure 6, left); by connex component, we mean a set of contiguous black pixels which are fully disconnected from the other components because white pixels surround them (please note that a dash is a connex component by itself). We then try to merge connex components that belong to the same implicit line segment. In this purpose, we use the well-known Tukey estimator [3] to compute the best line approximation for a given connex component; each dash is represented by a connex component and its best line approximation (its angle with the horizontal axis). We store the $x$ axis angles of all dashes in a circular histogram (each bin of the histogram represents a $5^{\circ}$ deviation), then we merge all the dashes in the same bin of the histogram. This merging process is divided in two cases: (i) for the angles of $0^{\circ}\left(\right.$ resp. $\left.90^{\circ}\right)$, we horizontally (resp. vertically) prolongate the dashes; (ii) for the oblique lines, we take all the pixels of the dashes falling in the same bin and compute the angle of the implicit line corresponding with these dashes with the horizontal axis, thus obtaining a better approximation of this line. As a result, the white regions in figure 6 (right) are fully surrounded by the implicit lines joining the dashes; these white regions represent the stairs of the stairwell (figure 6). If two adjacent connex components have two common points, we state that they represent two stairs with a high probability; thus we keep all the pixels belonging to these components, and their bounding box defines the bounding box of the staircase (figure 6, right).
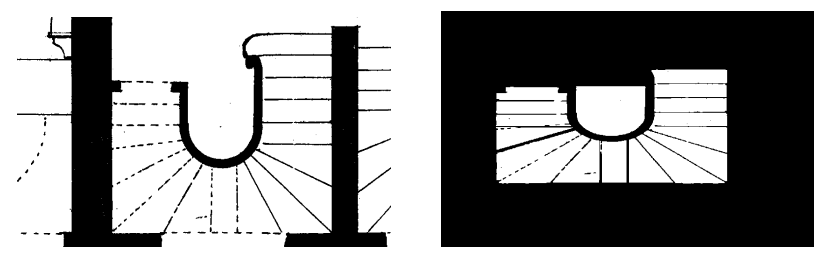

Fig. 6. Detection of staircase: results of the localization algorithm.

\section{3D RESTITUTION}

In section 4, we analyzed the floor plans and obtained a $2 \mathrm{D}$ vectorial representation of the main structures of the building. In the following paragraphs, we will build a 3D representation from the footprints detecting in the floor plans and using informations from the elevation and cut-off views. We do not intend to build a realistic 3D model, but only to give it a "pleasant" appearance in order that the user (particularly historians) could better understand the building. Nevertheless, even in very well-documented monuments such as the Château de Versailles, we will rarely find parts of the monument with a complete description for all the walls of the rooms.

\subsection{D extrusion}

A first 3D model is computed by simply extruding the walls on a given height (figure 7); the height of the walls is arbitrary fixed, and will be tuned thanks to the analysis of the elevation images.

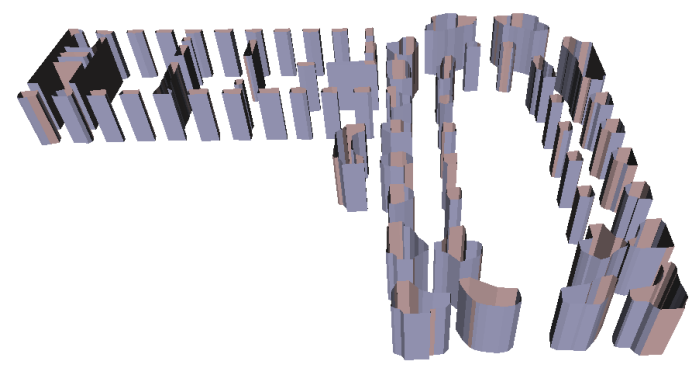

Fig. 7. 3D model of the walls detected in the original plan. 


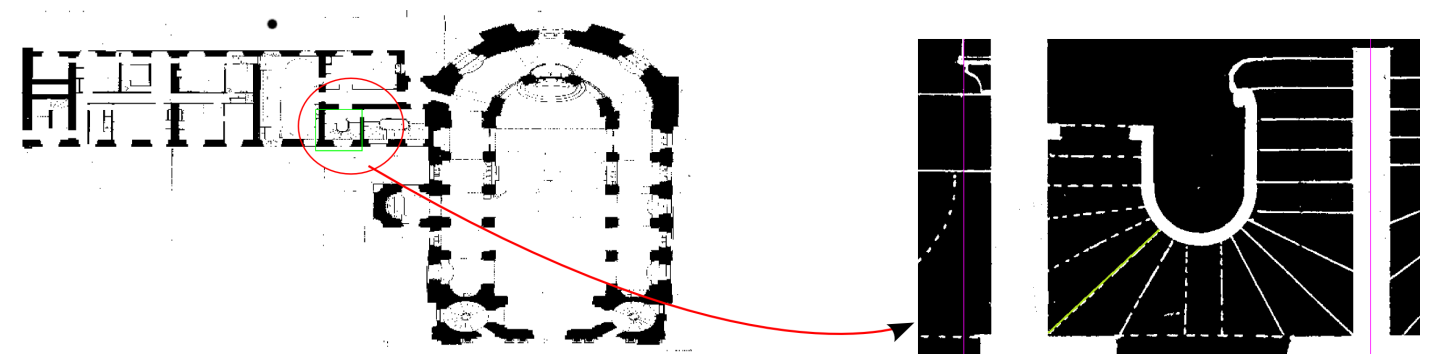

Fig. 5. Detection of staircase: the user first gives an approximate localization of the staircase.

\subsection{Texturing the $3 D$ model}

At this point of the process, each wall of the 3D model consists of two adjacent triangles constituting a rectangle. Additionally to the floor plans there are also several elevation plans of the castle representing vertical views of the rooms and the outside wall. The goal of the work presented in this section is to use the elevation plans (figure 8) to refine the vertical 3D representation of the walls of the monument.

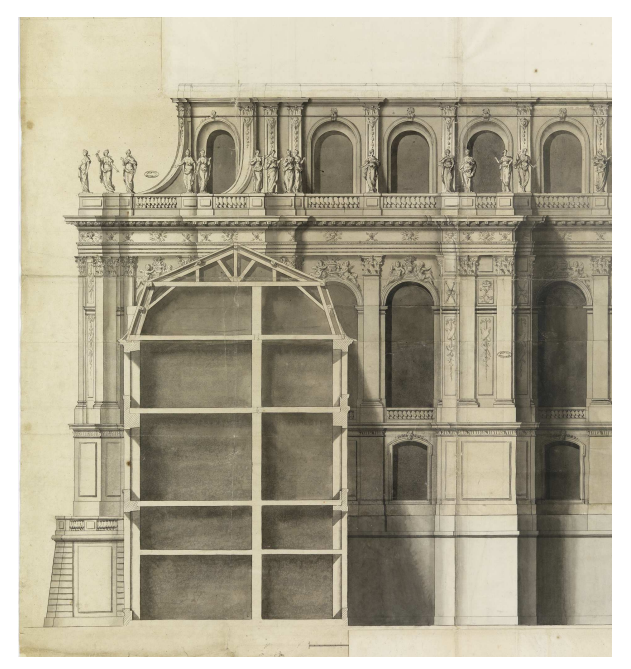

Fig. 8. Original elevation image.

The user interactively selects a wall or a set of walls on the primary 3D model and an approximatively corresponding rectangular region on the elevation image (figure 9). A vertical mesh of the selected walls is then automatically constructed and the older walls of the 3D primary model are replaced by the newly formed polygons. The elevation plan is also used to texture the new polygons. The vertices of the polygon are obtained from the points of the selected region in the elevation plan and this set of vertices is triangulated.

In order to compute the polygonalization of the vertical faces of the 3D model, we compute a 2D triangulation of the elevation image. We detect the contours of the interesting part of the elevation map thanks to a flooding algorithm, starting

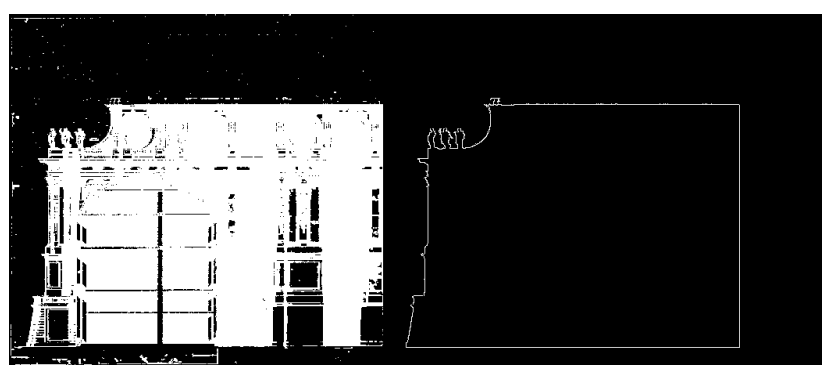

Fig. 9. The delimited boundary of the polygon.

from the upper-left corner of the image (supposed not to belonging to the interesting region) and an arbitrary point that the user select in the region. The boundary of the region is then triangulated by means of mathematical morphology operators.

The figure 10 presents the 3D model with a wall textured with the elevation image triangulated as explained in this section.

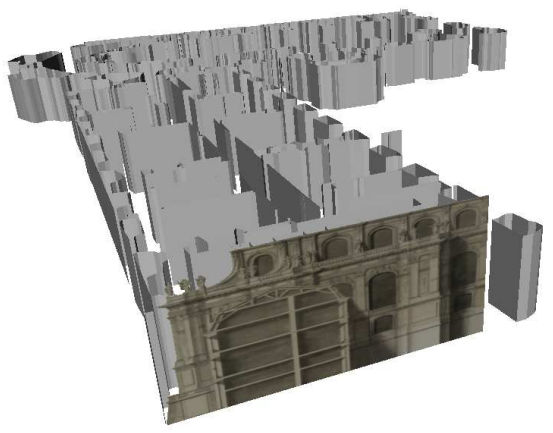

Fig. 10. 3D model with one elevation wall.

We used the same algorithm to analyze elevation images representing the inner sides of the rooms, in order to detect doors, windows, fireplaces, or other remarkable objects. 


\section{RESULTS}

We first applied the algorithms presented in this paper to images of the Château de Versailles, thanks to a collaboration with the Research center of the Château de Versailles (CRCV), the french National Archives and the french National Library $(\mathrm{BnF})$. We present in this section results computed on two different parts of the Château: the chapel and the "Appartement du Roy”.

\subsection{Château de Versailles}

The algorithm were developed in Java, and tested on a biXeon $2.4 \mathrm{GHz}$ processor. We present in table 1 the computation times for the 3D modeling of the "Appartement du Roy" (original floor plan image resized to $2600 \times 3700$ ).

We show on figure 11 different views of the "Appartement du Roy", either general or detailed view of the "Chambre du Roy", the 3D model is textured with the available data for two walls of the "Chambre" (bedroom). In this room, there is a balustrade in front of the king's bed, that we detected in the floor plan as a dividing wall, we fixed its height by computing it in comparison of the height of the room on the elevation image (figure 11, lower-right). The 3D model of the Chapel is in figure 12 .
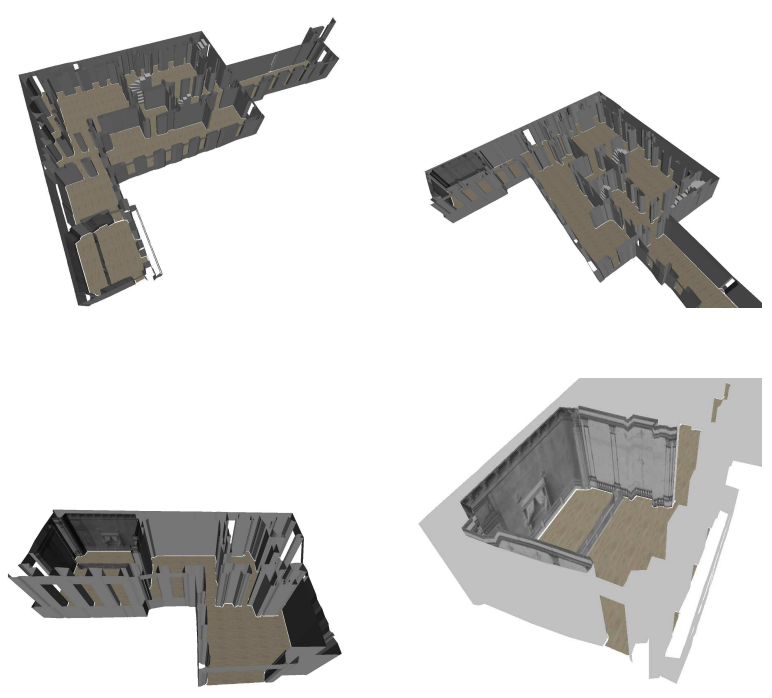

Fig. 11. 3D model of the "Appartement du Roy", with general views and details on the "Chambre du Roy".

\subsection{Results on other data}

We also checked our algorithms on data from other sources. For instance, we present in figure 13 the result of the floor plan analysis of a house in Aix-en-Provence (document from the Bibliothèque nationale de France). The size of this floor plan is significantly lower than the size of the floor plan of
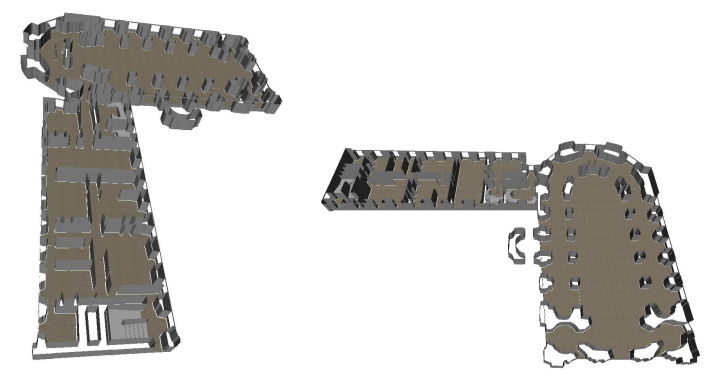

Fig. 12. 3D model of the Chapel of the Château de Versailles.

Versailles, thus we did not perform a size reduction. These results show that our algorithms are robust enough to be used on various data sources.
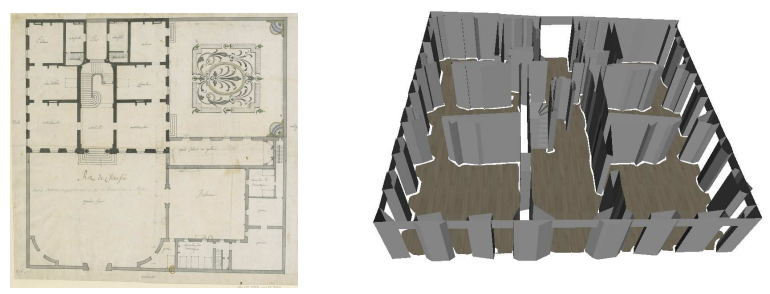

Fig. 13. Floor plan of the Hôtel de Caumont, and 3D model.

\section{CONCLUSION AND PERSPECTIVES}

We presented here a pipeline of an automated process towards 3D models of historical buildings such as royal castles from old floor plans. Image processing algorithms based on morphological mathematics allow to extract 2D informations from the plans, such as exterior and inner walls. Dedicated tools filter text areas.

Documents not only involves plans, but also cross-sections and elevations. A database will register links between the various documents describing each part of the castle, and links between $2 \mathrm{D}$ features computed from the digitized plans, thus leading to 3D models of different rooms of the monument. Nevertheless, historians know that these old plans are not technical drawings as architects use nowadays, and that there was often a "gap" between these drawings and the actual building, especially concerning the proportions of the rooms; thus we do not intend to produce "hyper-realistic" 3D views of the buildings, but only to give quite a good idea of their appearance and their internal organization at the time of the plans.

These 3D models will help historians to better understand the life in these castles in the past centuries; in fact, longliving historical buildings have changed over the years, due to the various usage of them (habitation, royal power place, national palace, ...), parts of the monuments have been destroyed and rebuilt. Historians have documents about the life 


\begin{tabular}{|l|c|c|c|c|c|c|}
\hline \hline Image size & Preprocessing & Segmentation & Walls & Staircase & Extrusion & Textures \\
\hline $2600 \times 3700$ & $10 \mathrm{~s}$ & $25 \mathrm{~s}$ & $61 \mathrm{~s}$ & $1,5 \mathrm{~s}$ & $1 \mathrm{~s}$ & $20 \mathrm{~s}$ \\
\hline \hline
\end{tabular}

Table 1. Computation times.

in these buildings which can not be explained by looking at their current appearance and organization. We hope that 3D models of their disappeared state(s) will provide a great benefit for those who are working on these old documents. Moreover, 3D models could also be interesting for general purpose, such as virtual visits: people will be able to visit a castle as it was in the past centuries, according to the documents that architects of these times has left for us!

\section{Acknowledgments}

VERSPERA is a research project funded by the PATRIMA french Labex and the "Fondation pour les Sciences du Patrimoine" (Sciences for Material Cultural Heritage). We particularly thank the Centre de recherche du Château de Versailles, the Archives nationales and the Bibliothèque nationale de France, for providing us images, data and historical informations.

\section{REFERENCES}

[1] Three dimensional monuments, programme national de numérisation du patrimoine. http://www.map.archi.fr/3D-monuments/.

[2] Sheraz Ahmed, Markus Weber, Marcus Liwicki, Christoph Langenhan, Andreas Dengel, and Frank Petzold. Automatic analysis and sketch-based retrieval of architectural floor plans. Pattern Recognition Letters (PRL), 35:91-100, 2014.

[3] A.E. Beaton and J.W. Tukey. The fitting of power series, meaning polynomials, illustrated on bandspectroscopic data. Technometrics, 16:147-185, 1974.

[4] Cluny numérique. http://clunynumerique.fr/gunzo/restitution-archeologique/cluny-iii.

[5] John Cosmas, Take Itegaki, Damian Green, Edward Grabczewski, Fred Weimer, Luc Van Gool, Alexy Zalesny, Desi Vanrintel, Franz Leberl, Markus Grabner, Konrad Schindler, Konrad Karner, Michael Gervautz, Stefan Hynst, Marc Waelkens, Marc Pollefeys, Roland DeGeest, Robert Sablatnig, and Martin Kampel. 3D MURALE: A Multimedia System for Archaeology. In Proceedings of the 2001 Conference on Virtual Reality, Archeology, and Cultural Heritage, VAST '01, pages 297-306, New York, NY, USA, 2001. ACM.
[6] Philippe Dosch, Karl Tombre, Christian Ah-Soon, and Gérald Masini. A complete system for the analysis of architectural drawings. International Journal on Document Analysis and Recognition, 3(2), 2000.

[7] Ricardo Fabbri, Luciano Da F. Costa, Julio C. Torelli, and Odemir M. Bruno. 2d euclidean distance transform algorithms: A comparative survey. ACM Comput. Surv., 40(1):2:1-2:44, February 2008.

[8] Tiantian Guo, Hui Zhang, and Yamei Wen. An improved example-driven symbol recognition approach in engineering drawings. Computers \& Graphics, 36(7):835845, 2012. Augmented Reality Computer Graphics in China.

[9] C.T. Huang and O.R. Mitchell. A euclidean distance transform using grayscale morphology decomposition. Pattern Analysis and Machine Intelligence, IEEE Transactions on, 16(4):443-448, 1994.

[10] J. Landrieu, C. Père, J. Rollier-Hanselmann, and G. Schotte. Reconstitution virtuelle de l'église abbatiale Cluny III: des fouilles archéologiques aux algorithmes de l'imagerie. In Actes du Colloque Virtual Retrospect 2009, pages 151-159, Pessac, France, 2010. Ausonius éd.

[11] Sébastien Macé, Hervé Locteau, Ernest Valveny, and Salvatore Tabbone. A System to Detect Rooms in Architectural Floor Plan Images. In IAPR International Workshop on Document Analysis Systems - DAS 2010, ACM International Conference Proceedings Series, pages 167-174, Boston, MA, États-Unis, June 2010. ACM.

[12] Siu-Hang Or, K.H. Wong, Ying-kin Yu, Michael Mingyuan Chang, and $\mathrm{H}$ Kong. Highly Automatic Approach to Architectural Floorplan Image Understanding \& Model Generation. In Proceedings of Vision, Modeling and Visualization, VMV'2005, Erlangen, Germany, 2005.

[13] Fabio Remondino. Heritage Recording and 3D Modeling with Photogrammetry and 3D Scanning. Remote Sensing, 3(6):1104-1138, 2011.

[14] Pierre Soille. Morphological Image Analysis: Principles and Applications. Springer-Verlag New York, Inc., Secaucus, NJ, USA, 2 edition, 2003. 
[15] David Tingdahl, Maarten Vergauwen, and Luc Van Gool. Arc3d: A public web service that turns photos into $3 \mathrm{~d}$ models. Digital Imaging for Cultural Heritage Preservation: Analysis, Restoration, and Reconstruction of Ancient Artworks, page 101, 2011.

[16] Lu Tong, Tai Chiew-Lan, Su Feng, and Cai Shijie. A new recognition model for electronic architectural drawings. Computer-Aided Design, 37(10):1053 - 1069, 2005.

[17] D. Van De Ville and M. Kocher. Sure-based non-local means. Signal Processing Letters, IEEE, 16(11):973976, 2009.

[18] Luc Van Gool and Robert Sablatnig. Special issue on 3d acquisition technology for cultural heritage. Machine Vision and Applications, 17(6):347-348, 2006.

[19] Y. Xuetao, P. Wonka, and A. Razdan. Generating 3D Building Models from Architectural Drawings: A Survey. Computer Graphics and Applications, IEEE, 29, 2009.

[20] N. Yastikli, O. Emem, and V. Alki. 3D model generation and visualization of cultural heritage. Int. Archives of the Photogrammetry, Remote Sensing and Spatial Information Sciences, XXXIV-5/C15:1682-1777, 2003.

[21] Junfang Zhu, Hui Zhang, and Yamei Wen. A new reconstruction method for 3D buildings from $2 \mathrm{D}$ vector floor plan. In Computer-Aided Design and Applications 2013, Lombary, Italie, June 2013. 